\title{
Density and Molar Volume of Molten Ni-Based Commercial Alloys Measured by Modified Sessile Drop Method
}

\author{
Xiao Feng ${ }^{1}, \quad$ Yang Renhui ${ }^{1}, \quad$ Liu Lanxiao ${ }^{1}, \quad$ Zhao Hongkai ${ }^{1}, \quad$ Fang Liang $^{2}, \quad$ Zhang Chi $^{1}$ \\ ${ }^{1}$ Chongqing Institute of Technology, Chongqing 400050, China; ${ }^{2}$ Chongqing University, Chongqing 400044, China
}

\begin{abstract}
The densities of four kinds of molten Ni-based commercial alloys were measured with a modified sessile drop method, and calculated using the calculating software. It is found that the densities of the molten Ni-based commercial alloys decrease and their molar volume increase with increasing of temperature. Compared with the ideal mixing, the molar volumes of the molten Ni-based commercial alloys show negative deviations. It can be attributed to an accommodation between various atoms in the alloys.
\end{abstract}

Key words: Ni-based commercial alloys; density; sessile drop method; molar volume

Ni-based commercial alloys are widely used in high temperature and corrosive environments such as gas turbine engines and heat exchangers, while they are very hard and difficult to be machined. The net-shape casting of the alloys is often used because of its cheap process. It is essential to measure the thermophysical properties such as density, surface tension, viscosity etc. of molten Ni-based commercial alloys to obtain low-cost net-shape casting ingot without inner porosity. With the advent of powerful mathematical modeling techniques for material phenomena, there is renewed interest in reliable data for the densities of the Ni-based superalloys. In present years, the densities of molten Ni-based model alloys such as Ni-(Cr, Co, W, Ta, Al) binary, ternary or quaternary alloys were measured ${ }^{[1-15]}$. However, there are only a few of the data on the densities of molten Ni-based commercial alloys, which were measured by Mukai et al. ${ }^{[12]}$ with modified sessile drop method. In this paper, the densities of four kinds of molten Ni-based commercial alloys were measured with the modified sessile drop method and their molar volumes were calculated.

\section{Experimental}

The chemical compositions for the four kinds of the Ni-based commercial alloy are shown in Table 1.
The principle of the modified sessile drop method is shown in Fig.1, which was introduced in other paper in detail ${ }^{[14]}$. A sample was charged into a horizontal alumina crucible. When the temperature of the furnace was higher than the liquidus temperature of the alloy, a drop with smooth surface was formed at the upper end of the crucible. Then, from the photo of sample, the density of alloy, $\rho$ in $\mathrm{Mg} \cdot \mathrm{m}^{-3}$, could be calculated by the following equation:

$$
\rho=\frac{m}{V_{1}+V_{2}}
$$

Where $m$ is the sample mass, in $\mathrm{Mg}, V_{1}$ the inner volume of crucible at experimental temperature and $V_{2}$ the volume of sample formed at the upper end of the crucible, in $\mathrm{m}^{3}$.

The experimental apparatus consisted of a $\mathrm{LaCrO}_{3}$ heating furnace, a gas purifier, an oxygen sensor and a photographic system, and an error for the method is estimated as $\pm 0.75 \%{ }^{[14]}$.

\section{Results and Discussion}

\subsection{Density of molten Ni-based commercial alloys}

The density data of the molten Ni-based commercial alloys measured in this study is given in Fig.2.

The densities of molten alloys decrease with increasing of temperature. Steinberg ${ }^{[16]}$ proposed that the density data of

\footnotetext{
Received date: May 20, 2008

Foundation item: Supported by Scientific Research Foundation for the Returned Overseas Chinese Scholars (2004527), the Chongqing Bureau of Personal(200594), the Natural Science Foundation of Chongqing Municipality (CSTC2005BA4016-1) and the Chongqing Institute of Technology (2003ZD31) Biography: Xiao Feng, Ph. D., Professor, Materials Interfacial Physical-Chemistry Research Institute, Chongqing Institute of Technology, Chongqing 400050, P. R. China, Tel:0086-23-66966286, E-mail: xiaofeng@cqit.edu.cn 
Table 1 Composition of Ni-based commercial alloys $(\omega / \%)$

\begin{tabular}{ccccccccccccccc}
\hline \multirow{2}{*}{ Alloy } & \multicolumn{10}{c}{ Composition } \\
\cline { 2 - 12 } & $\mathrm{Cr}$ & Mo & $\mathrm{Al}$ & $\mathrm{Co}$ & $\mathrm{W}$ & $\mathrm{B}$ & $\mathrm{Zr}$ & $\mathrm{Ta}$ & $\mathrm{Hf}$ & $\mathrm{Ti}$ & $\mathrm{C}$ & $\mathrm{Re}$ & $\mathrm{B}$ & $\mathrm{Ni}$ \\
\hline INCO713C & 14.5 & 4.2 & 6.1 & & & & 0.01 & & & 0.8 & 0.12 & 0.012 & Balance \\
CM247LC & 8.1 & 0.5 & 5.6 & 9.2 & 9.5 & 0.015 & 0.015 & 3.2 & 1.4 & 0.7 & & & Balance \\
CMSX-4 & 6.5 & 0.6 & 5.6 & 9 & 6 & & & 6.5 & 0.1 & 1 & & 3 & Balance \\
TMS75 & 3 & 2 & 6 & 12 & 6 & & & 6 & & & & 5 & Balance \\
\hline
\end{tabular}

molten allos could be represented by the following equation:

$$
\rho=\rho_{\mathrm{L}}+k\left(T-T_{\mathrm{L}}\right)
$$

Where $\rho_{\mathrm{L}},\left(\mathrm{Mg} \cdot \mathrm{m}^{-3}\right)$, stands for the density at the liquids temperature $T_{\mathrm{L}}$, and $k\left(\mathrm{Mg} \cdot \mathrm{m}^{-3} \cdot \mathrm{K}^{-1}\right)$ is the temperature coefficient of the density at constant pressure which is

$$
k=(\partial \rho / \partial T)_{P}
$$

Where $T$ is the temperature in Kelvin scale.

If we follow Steinberg formula, the densities of molten Ni-based commercial alloys measured in this study can be described as follows:

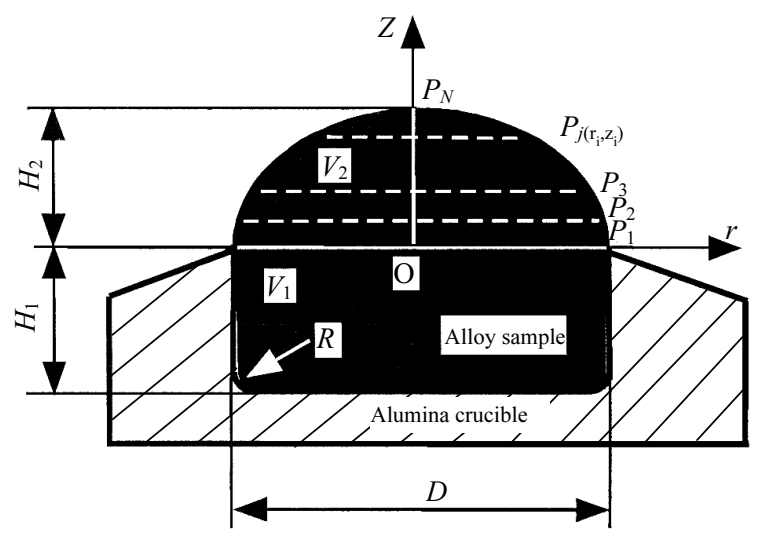

Fig.1 Schematic of modified sessile drop method for measurement of the density

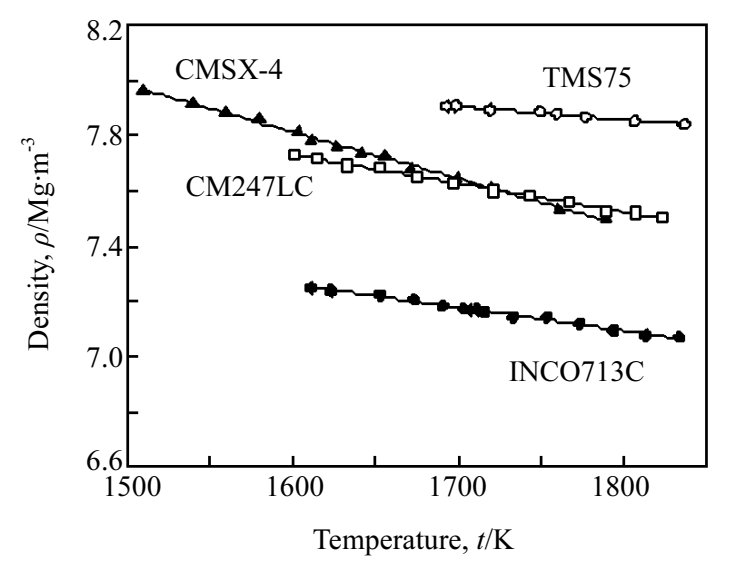

Fig.2 Temperature dependence of the density of Ni-based commercial alloys

$\begin{array}{lc}\text { INCO713C } & \rho=8.59-8.33 \times 10^{-4} T \\ \text { CMSX-4 } & \rho=10.52-1.69 \times 10^{-3} T \\ \text { TMS75 } & \rho=8.69-4.65 \times 10^{-4} T \\ \text { CM247LC } & \rho=9.39-1.04 \times 10^{-3} T\end{array}$

Of all the elements in Table.1, the densities of $\mathrm{W}$ and Ta are bigger than that of others. The bigger the $(\mathrm{W}+\mathrm{Ta}) \%$ is, the bigger the density of the alloy is. The element content and $(\mathrm{W}+\mathrm{Ta}) \%$ in CMSX-4 are similar to that of CM247LC. As a result, the density of CMSX-4 is close to that of CM247LC. Compared with CMSX-4 and CM247LC, there is no $\mathrm{W}$ and Ta in $\mathrm{INCO} 713 \mathrm{C}$, and the concentrations of $\mathrm{Ni}$ and $\mathrm{Cr}$, are higher. Therefore, the density of INCO713C is relatively smaller. $(\mathrm{W}+\mathrm{Ta}) \%$ in TMS75 is similar to that in CMSX-4 and CM247LC. But due to less $\mathrm{Cr}$ and more Mo in TMS75, the density of TMS75 is the biggest of the four commercial alloys.

In order to estimate the densities of alloys, many softwares have been developed and applied in various fields. In present work, the densities of the four kinds of the commercial alloys can be calculated using the software named METALS developed by Mills et al. and the results are shown in Fig.3. The calculated values of the densities are always smaller than experimental values. The maximum difference between calculated value and experimental value is about $13.8 \%$. Up to date, the calculating software is always designed under an assumption that the alloy is an ideal mixture of its composition. Actually, the alloy is a nonideal mixture of various chemical elements. This is the primary reason why so much deviation between calculated values and experimental values exist.

\subsection{Molar volume for molten Ni-based commercial alloys}

The molar volume of the molten Ni-based commercial alloys can be calculated from the molar mass and the density data of the allos by the following equation :

$$
V_{\text {mol }}=\frac{M_{\text {Alloy }}}{\rho_{\text {Alloy }}}
$$

Where $V_{\text {mol }}, M_{\text {Alloy }}$ and $\rho_{\text {Alloy }}$ stand for the molar volume, the molar mass and the density of the alloy, respectively. Inserting the values for $M_{\text {Alloy }}$ and $\rho_{\text {Alloy }}$ for each alloy into Eq.(8), the molar volumes of the alloys can be expressed as follows:

$$
V_{\text {mol }}(\mathrm{INCO} 713 \mathrm{C})=\frac{54.58}{8.59-8.33 \times 10^{-4} T}
$$




$$
\begin{aligned}
& V_{\mathrm{mol}}(\mathrm{CMSX}-4)=\frac{59.33}{10.52-1.69 \times 10^{-3} T} \\
& V_{\mathrm{mol}}(\mathrm{TMS} 75)=\frac{59.65}{8.69-4.65 \times 10^{-4} T} \\
& V_{\mathrm{mol}}(\mathrm{CM} 247 \mathrm{LC})=\frac{59.30}{9.39-1.04 \times 10^{-3} T}
\end{aligned}
$$

The molar volumes of the Ni-based commercial alloys are plotted in Fig.4. The molar volume of Ni-based commercial alloys trends to increase with increasing of temperature.

The study of the accommodation among atomic species is an important task, which is expressed as a deviation $\left(\Delta V_{\text {mix }}\right)$, of the liquid solution from ideal volumetric mixing.

$$
\Delta V_{\text {mix }}=V_{\text {mol }}-V_{\text {ideal }}
$$

Where $V_{\text {mol }}$ is the molar volume calculated from the density and $V_{\text {ideal }}$ the molar volume in ideal volumetric mixing.

For the Ni-based commercial alloys there is a following relationship:

$$
\Delta V_{\text {mix }}=\frac{\sum X_{i} M_{i}}{\rho_{\text {Alloy }}}-\sum \frac{X_{i} M_{i}}{\rho_{i}}
$$

Where $X_{i}$ and $M_{i}$ are the molar fractions and molar mass of alloy elements, respectively. $\rho_{\text {Alloy }}$ and $\rho_{i}$ are the density of Ni-based alloys and alloy element, respectively. Because some elements such $\mathrm{W}$ and $\mathrm{Cr}$ do not exist in the liquid state at the experimental temperature, it is difficult to strictly verify the molar volume in Eq.(14) in the molten alloy system. However, it is assumed that the relationship proposed by Levin et al. ${ }^{[17]}$ can be used to calculate their densities in the metastable state at the temperature lower than melting point; the deviation of the molar volume from ideal mixing can be shown in Fig.5. The molar volumes of molten Ni-based commercial alloys determined in the present work show negative deviations from the ideal molar volume, which means that the alloy elements are mixed nonideally. From an elementary standpoint, it might be presumed that a negative $\Delta V_{\text {mix }}$ of the alloy means an accommodation among various atoms.

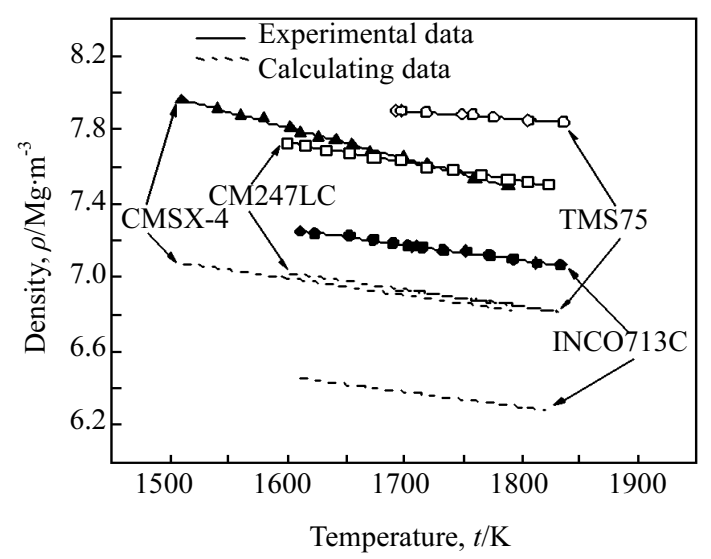

Fig.3 Measured density values and calculated density values with software

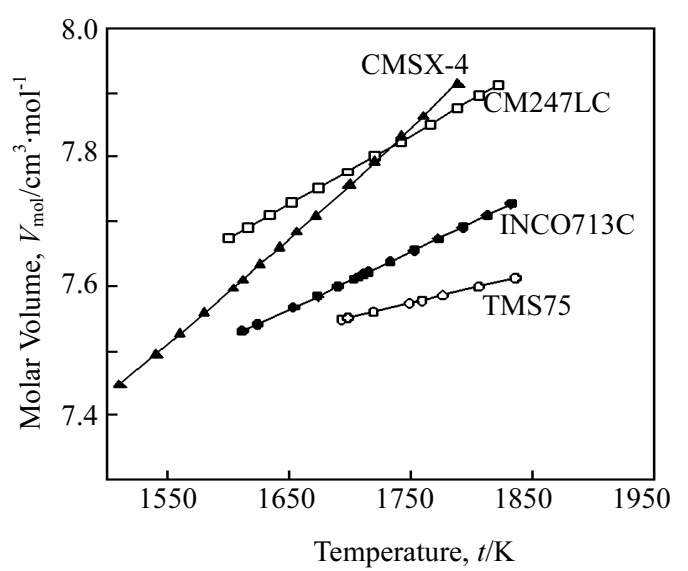

Fig.4 Temperature dependence of molar volume of Ni-based commercial alloys

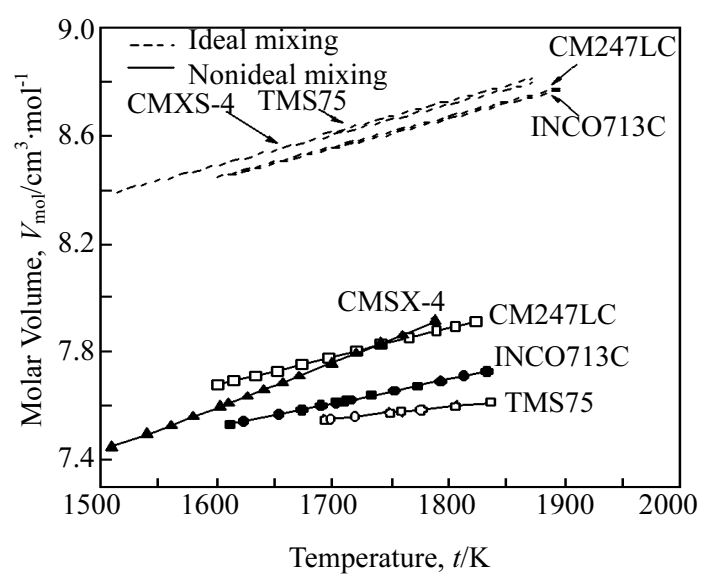

Fig.5 Deviation of molar volume from ideal mixing in Ni-based commercial alloys

\section{Conclusions}

1) Density of molten Ni-based commercial alloys can be measured with a modified sessile drop method. The density of molten alloys trends to decrease with increasing of temperature.

2) The molar volumes of Ni-based commercial alloys increase with increasing of temperature. Compared with the ideal mixing, the molar volumes of molten Ni-based commercial alloys show a negative deviation.

\section{References}

1 Xiao F. Journal of Materials Science and Technology[J], 2004, 20(4): 410

2 Xiao F, Fang L. Journal of Iron and Steel Research[J], 2004, 11(3):37

3 Xiao Feng, Fang Liang. Journal of Materials Science and Technology [J], 2003, 19(5):388 
4 Xiao F. Journal of Materials Science and Technology[J], 2003, 19(2): 107

5 Xiao F. Journal of Materials Science and Technology[J], 2003, 19(1): 16

6 Fang Liang(方 亮) et al. Wuhan University of Technology(武汉 科技大学学报) [J], 2005, 20(3):84

7 Fang Liang(方 亮) et al. Rare Metal Materials and Engineering （稀有金属材料与工程）[J], 2005, 34(4):521

8 Fang Liang(方 亮) et al. Wuhan University of Technology(武汉 科技大学学报)[J], 2005, 20(2):67

9 Fang Liang(方 亮) et al. Rare Metal Materials and Engineering （稀有金属材料与工程）[J], 2004, 33(12):1261
10 Fang L, Xiao F. Journal of Materials Science and Technology[J], 2004, 20(4): 405

11 Fang L et al. Journal of Materials Science and Technology[J], 2004, 20(3): 287

12 Mukai K et al. Materials Transactions JIM[J], 2004,45(10):2987

13 Mukai K et al. Materials Transactions JIM[J], 2004, 45(5):1754

14 Mukai K et al. Materials Transactions JIM[J], 2002, 43(5):1153

15 Mukai K et al. Materials Transactions JIM[J], 2004, 45:2357

16 Steinberg D J. Metallurgical Transactions A[J], 1974, 5:1341

17 Levin E S, Ayushina G D. Russian Journal of Physical Chemis$\operatorname{try}[\mathrm{J}], 1971,45: 792$

\title{
用改良静滴法测量液态 $\mathrm{Ni}$ 基合金的密度和摩尔体积
}

\author{
肖 锋 ${ }^{1}$, 杨仁辉 ${ }^{1}$, 刘兰霄 ${ }^{1}$, 赵红凯 ${ }^{1}$, 方 亮 $^{2}$, 张 弛 $^{1}$ \\ (1. 重庆工学院, 重庆 400050) \\ (2. 重庆大学, 重庆 400040)
}

\begin{abstract}
摘 要: 采用改良静滴法测量并通过软件的计算得到了 4 种商用镍基合金的密度。结果表明, 随着温度的升高, 4 种液态镍基合金的密 度逐渐减小，摩尔体积逐渐增大。与理想混合状态相比，液体镍基合金的摩尔体积出现负偏差。从而可以推测在合金中各种原子之间发 生了调整。
\end{abstract}

关键词：商用镍基合金; 密度; 静滴法; 摩尔体积

作者简介: 肖 锋, 男, 1970 年生, 博士, 教授, 重庆工学院材料界面物理化学研究所, 重庆 400050, 电话: 023-66966286, E-mail: xiaofeng@cqit.edu.cn 